\title{
MULHERES, FAMÍlIA E PODER: VELHAS PRÁTICAS DA POLÍTICA FORMAL NA PARAÍBA ${ }^{1}$
}

\author{
Cosma Ribeiro de Almeida ${ }^{2}$
}

\begin{abstract}
Resumo: $O$ artigo tem como principal objetivo refletir a entrada de mulheres na política, em especial no executivo municipal entre 2008 e 2012 na Paraíba, tendo em vista os laços familiares as quais estariam envolvidas e favorecidas para participarem do poder formal. A discussão é parte de uma pesquisa de campo realizada com cinco prefeitas, cujos relatos delas próprias nos mostram a dependência em relação aos familiares para ocuparem o cargo de gestora municipal. Neste sentido, nossa pesquisa é de abordagem quanti-qualitativa, e nos permite perceber que o papel social que as mulheres ocupam nas relações políticas representa as velhas práticas do parentesco político. Fazendo permanecer as antigas redes sociais de poderio tanto nos municípios como no Estado.
\end{abstract}

Palavras chave: Mulher. Política tradicional. Família. Poder.

\section{WOMEN, FAMILY AND POWER: OLD PRACTICES OF THE FORMAL POLICY IN PARAÍBA}

\begin{abstract}
The main objective of this article is to reflect the entry of women into politics, especially in the municipal executive between 2008 and 2012 in Paraíba, considering the family ties that would be involved and favored to participate in formal power. The discussion is part of a field survey carried out with five mayors, whose own reports show us the dependence on family members to occupy the position of municipal manager. In this sense, our research is of quantitative-qualitative approach, and it allows us to realize that the social role that women occupy in political relations represents the old practices of political kinship. Making the old social networks of power remain in the municipalities as well as in the State.
\end{abstract}

Keywords: Woman. Traditional politics. Family. Power.

- Enviado em 15/07/2017

- Aprovado em 28/07/2017

\footnotetext{
${ }^{1}$ Uma versão preliminar desse texto foi apresentada no $18^{\circ}$ Congresso Brasileiro de Sociologia. Que Sociologia fazemos? Interfaces com contextos locais, nacionais e globais realizado de 26 a 29 de julho de 2017 no Centro de Convenções Ulysses Guimarães, Brasília/DF.
}

2 Doutoranda no Programa de Pós-Graduação em Ciências Sociais da Universidade Federal de Campina Grande UFCG. Endereço eletrônico: cosma_almeida@yahoo.com.br 


\section{Introdução}

De acordo com os dados do Tribunal Superior Eleitoral - (TSE) desde os anos 2000 houve um crescimento de mulheres eleitas ao cargo de prefeita em todo o Brasil. Também ganha destaque a Paraíba que nas últimas eleições vem apresentando um crescimento do número de prefeitas, a exemplo do ano de 2012 que elegeu 48 mulheres ao cargo, estando entre os estados que mais elegeu mulheres para o governo municipal no país. Naquele mesmo ano, a região Nordeste elegeu 288 prefeitas no total.

Nos chama atenção o fato de que o Nordeste, bem como o estado da Paraíba, tem uma história política marcada pelo coronelismo e pelo patriarcalismo, cujas consequências também residem na forte perpetuação de famílias no poder local: as mesmas famílias comandando, durante décadas, a região e/ou cidades. Desde a primeira república, a Paraíba sempre foi comandada por grupos oligárquicos de poder. Atualmente as práticas se repetem com novos grupos políticos, o que comprova que velhas práticas estão presentes na história política local (LEWIN, 1993, apud RABAY, 2012).

Em relação à participação das mulheres na política partidária, ressaltamos a presença delas como sujeitos que ainda buscam seu espaço, pois estão submissas, na maioria dos casos, ao jogo de poder masculino da política. Vale ressaltar que o estudo sobre este tema ganha impulso desde os anos 1990, e hoje é possível, a partir de dados empíricos e históricos, entender esta presença no Brasil.

Lúcia Avelar (2001) nos ensina que a presença da mulher no espaço de poder se deve muitas vezes à relação de parentesco. Ou seja, uma vez o homem não podendo se candidatar a mulher seria uma opção para continuar o poder político da família e/ou do grupo político. Neste contexto, a relação "família, mulheres e poder" torna-se um segmento de estudo, dentre tantos outros, para entendermos a participação do feminino na política formal. É por este motivo que não pretendemos ousar em finalizar esta discussão aqui, mas entendermos que novos esboços continuam assim como novos olhares e reflexões sobre o tema.

Sobremaneira, o artigo é resultado de uma pesquisa de campo, realizada durante a coleta de dados para a Tese de Doutorado sobre a participação das mulheres na política local paraibana, especificamente do executivo municipal. Tal investigação in loco aconteceu em 2015 e 2016, em que foram entrevistadas cinco gestoras municipais, que por sua vez falaram da experiência de serem prefeitas e da função social que exerciam enquanto mulheres políticas. 
Pretendemos, no entanto, não revelar a identidade das prefeitas, tendo em vista que a aceitação delas para cederem a entrevista se deu sob a justificativa de que a investigação era sobre a inserção da mulher na política e a opinião delas sobre isso. A proximidade entre a presença delas na política e a relação com o parentesco, recorte tratado neste artigo, foi percebida nas informações que elas mesmas passavam durante as entrevistas. Sendo assim, compreendemos as falas destas prefeitas como um rico conjunto simbólico que diz muito sobre o lugar que elas ocupam no espaço de poder. É importante ressaltar que as gestoras municipais têm entre 38 e 65 anos de idade, são de religião católica, quatro dentre as cinco prefeitas têm parentes de primeiro grau na política, e todas elas ocuparam pela primeira vez um cargo político ao exercer a função de prefeita. São prefeitas de cidades do interior, distantes da capital, cuja economia é mínima, com uma população pequena e de difícil acessibilidade, de regiões da Mata Paraibana, Curimataú, Agreste e Cariri do Estado.

Tais mulheres afirmam a importância de estarem na política formal contribuindo, enquanto mulheres, para o desenvolvimento dos municípios os quais governam. Porém, não negam a imprescindível relação de parentesco que as projetaram para "dentro da política". Ou seja, contribuíram para o continuísmo do poder local, para os grupos de interesses dos quais começaram a fazer parte.

Neste contexto, entendemos que a entrada da mulher na política formal nem sempre significa conquista de direitos sociais e civis, pois muitas delas ocupam cargos públicos para continuarem a política partidária dos parentes, seja do pai, do esposo, do tio, ou irmão político. Podemos afirmar que apesar de muitas conquistas por parte das mulheres no campo dos direitos sociais, a participação delas na política formal contribui para a permanência de velhas práticas da política paraibana, tal como a reprodução da dominação masculina do poder e o poderio dos grupos políticos que durante décadas comandam regiões interioranas no estado da Paraíba.

Percebe-se uma "coincidência" nos discursos das mulheres quanto às suas justificativas de participarem do espaço de poder. Dentre os parâmetros que têm para estarem governando um município está a conduta dos parentes políticos que a ajudaram, ou seja, sentem-se "seguras" à imagem pública de um homem que lhes serve de exemplo de figura política. 


\section{A família como "ponte" para a política formal}

Segundo o pesquisador Ricardo Costa Oliveira (2016, p. 14) as mulheres cumprem um papel muito importante na reprodução da família. As constituições dos papéis sociais atribuídos à homens e mulheres colocam estas últimas no cenário dos sentimentos, das emoções. "As estratégias familiares e de classe passam em boa parte pelas ações sociais e políticas das mulheres das grandes famílias, em suas próprias políticas estratégicas, sejam elas muito antigas ou relativamente recentes".

Neste sentido, é pertinente observar a partir das palavras das próprias prefeitas a exemplo "na política cheguei e casei” como uma confirmação de laços familiares, de alianças de poder familiar sendo organizados dentro da política partidária ou mesmo antes da "entrada" delas na política. Embora haja prefeita que afirme que o marido não teve influência na sua campanha eleitoral, confirma ao mesmo tempo a ideia de que muitas mulheres ainda dependem de seus companheiros para participarem da política partidária: "a mulher na política, a maioria, não tem experiência, a maioria a experiência é do marido".

O papel social e político das mulheres nas relações e conexões sociais entre os emergentes e as velhas estruturas de poder são dimensões centrais. As mulheres representam formas tradicionais de sociabilidades e de pertencimentos às antigas redes sociais e políticas (OLIVEIRA, 2016, p. 17).

Percebe-se, principalmente em cidades interioranas da Paraíba, o nepotismo como uma prática comum, cuja relação social e política estão baseadas na prática do clientelismo. $\mathrm{O}$ atraso econômico dessas cidades do interior também é um fator que contribui para tal patronato, pois a economia e o desenvolvimento descrescente são características destes municípios. São nestes espaços que surgem a maior presença das mulheres na política municipal, as prefeitas acreditam que exercem um papel importante na cidade, mas também acreditam no nome da família a qual pertencem, sejam "carregando" o sobrenome do esposo, do pai, de um irmão ou de um tio.

A exemplo desta assertiva, podemos observar na fala de uma das gestoras públicas:

Meu pai já foi prefeito, o irmão do meu pai já foi prefeito duas vezes, meu tio foi prefeito quatro vezes, meu irmão é vereador no sexto mandato vai para o sétimo. Nós somos tradicionalmente políticos. 
A fala "minha família é tradicionalmente política" nos mostra o jogo de herança como uma transferência de um determinado capital simbólico. Como muitos membros da família já foram políticos seria "normal” que ela (a mulher) também exercesse o cargo público. Tal herança acontece de uma forma complexa, pois envolve não apenas interesses de parentescos mas também de partidos políticos, bem como a influência de coligações partidárias.

A influência nesse contexto pode ser vista como transferência de créditos, na medida em que o desejo do mandante opera a partir da tentativa de persuasão. Nesse caso, pode-se falar de prestígio ou capacidade de instituir uma herança simbólica baseada na confiança (BARREIRA, 2008, p. 119).

Neste sentido, as palavras da mesma prefeita são significativas quando diz:

Meu irmão é um incentivador, meu marido também. (...) Essa preocupação (do povo) é uma preocupação nossa (minha e do meu irmão) por que nós fomos quase trinta anos oposição aos meus dois tios, então nós tínhamos já essa ideia de um dia chegar onde nós estamos, sendo que fosse ele (o irmão), mas surgiu o meu nome e sem problema nenhum ele foi um dos incentivadores e hoje eu estou aqui. (Grifo nosso).

Ora, a fala deixa implícito que o nome da candidata foi escolhido para o jogo político partidário da cidade, o que comprova a sua ausência na tomada de decisão é o fato de dizer que pretende "voltar a exercer a profissão que exercia antes de entrar na política", o de professora da educação básica. E com isso pretenderia "passar" o cargo para o irmão que a incentivou e é o viceprefeito dela.

Sobre essa questão Ricardo Costa Oliveira (2016, p. 16) afirma que:

O protagonismo das mulheres e suas redes sociais e políticas também podem ser analisados ao lado do protagonismo dos homens, que suas habilidades e "méritos" específicos galgaram relevantes posições sociais e políticas.

A realidade que cerca a vida pública das prefeitas está calcada em estruturas também de família, de jogos de parentesco, que contribuem para uma realidade social e política também para elas. Este fenômeno de inserir a mulher na política através do interesse familiar é um modo de controlar a liderança do poder executivo municipal, numa tentativa de passar este controle de gestão pública de geração para geração. 
As elites fazem as mudanças, buscando entre as maiorias dominadas os elementos para fazer a substituição de seus membros, permitindo assim a circulação entre os grupos. De tempos em tempos alguém da classe governada ascende à classe governante e passa a agir de acordo com a nova classe. Para os governados há uma aparente ascensão, que na verdade, serve apenas para manter o status quo (BERNARDI, 2015, p. 25 apud BERNARDI, 2016, p. 343).

As mulheres que participam da política no executivo municipal não rompem com as velhas estruturas patriarcais, mas os reforçam com o "novo papel” que assumem na gestão pública. As possibilidades que aparecem para estas mulheres são mínimas, o que as impedem muitas vezes de terem uma gestão com autonomia que atendam realmente as necessidades da população local.

Diante de tal realidade é possível compreender que a maior parte das prefeitas paraibanas foi eleita através de laços políticos familiares, ou seja, do jogo político que envolve a sucessão de poder dos parentes. Sabemos que os homens, da mesma forma que as mulheres, também têm uma grande inserção na política através dos laços e interesses familiares. Mas o que chama atenção é o fato de que as mulheres quando comparadas aos homens tem menores acessos para a política formal e sofrem uma série de barreiras para chegarem aos âmbitos de poder da sociedade. E quando entram na política, muitas vezes, é pela via do parentesco, usando o "nome forte da família" para poderem se fazer representar. Assim, sob este aspecto o núcleo familiar continua sendo muito importante na cultura política local, pois

a família continua constituindo o núcleo básico da nossa cultura. (...) As emoções, as atitudes e as crenças enraizadas na família explicam a coerência do nosso sistema cultural, constituem um verdadeiro elemento social. Parece, pois, necessário que a sociedade as mantenham vivas, por que disso depende a vida e morte da civilização na sua forma atual (HORKHEIMER, 1994, p. 179 apud COSTA, 1998, p. 155).

Neste sentido, a família é vista como um elemento fundamental para fazer permanecer também determinados rituais políticos, inclusive o uso do sobrenome como um forte signo nas disputas eleitorais.

No Nordeste, pelo menos, entre as classes dominantes (...) a família "moderna" guarda fortes características da família patriarcal dominante durante os períodos colonial e imperial, não só quanto à sua organização mas também no que se refere à manutenção de uma estrutura de poder baseada no domínio quase absoluto do pai. Essa família, organizada com base no grupo doméstico, incorporando a seu núcleo central, membros originários de outras relações sociais que não são 
estabelecidas pelos laços de consanguinidade, tem por objetivo, além da função socializadora, o controle político da sociedade (COSTA, 1998, p. 157).

No Nordeste brasileiro, e também na Paraíba, a família tem um papel relevante na concretização do poder político tradicional, sendo esta uma das características de fazer política principalmente nas cidades do interior. A transmissão da "herança política" é uma afirmação da permanência de grupos oligárquicos ou continuísmo daqueles que estão no poder político. Como afirma Irlys Barreira (2008, p. 100) é o fato de fazer um sucessor a fim de garantir a longevidade da herança política familiar, considerado "uma espécie de ação patrimonial”.

A transferência de herança simboliza aquilo que está cristalizado na cultura, uma cessão de patrimônio de família sendo repassada para futuras gerações, como afirma Glória Rabay (2012, p. 64):

Considerando a herança como o processo de transmissão de um patrimônio de uma geração à outra, ou de uma pessoa a outra, não necessariamente em virtude de morte do proprietário e nem apenas composta de bens materiais, as práticas de transmissão de herança podem dizer muito a respeito da cultura e da forma como o poder é distribuído na sociedade.

Neste caso, o que estaria em jogo não seria uma herança material, mas uma herança símbolo, o capital simbólico do poder político local (no município). Capital simbólico é o "crédito firmado na crença e no reconhecimento ou, mais precisamente, nas inúmeras operações de crédito pelas quais os agentes conferem a uma pessoa - ou a um objeto - os próprios poderes que eles reconhecem" (BOURDIEU, 2011, p. 187).

De qualquer modo, tal herança não deixa de ser uma conquista para as mulheres: primeiro por que conquistaram o capital simbólico para poder gerir a prefeitura da cidade; depois porque no Brasil, do século XX, a herança política pertencia apenas aos filhos, ou seja, os homens é quem herdavam este patrimônio familiar. E hoje, sendo as mulheres pensadas como herdeiras do grupo político é um fenômeno que merece reflexão como uma nova prática da ação política.

Uma das prefeitas ao afirmar que "começou a gostar da política por que via seu pai atuando" mostra o mecanismo de identificação com o político e a partir do momento que o pai a convida para ser candidata em sua vaga, ela passa também a ser herdeira política da família. As conversas com o pai sobre gestão pública a ajudou a gostar do campo que jamais imaginava participar, possibilitando o continuísmo do projeto político do grupo familiar e não o seu próprio enquanto candidata ou 
prefeita do município. Aquele (a) que foi designado para continuar o poder familiar é "símbolo da perpetuação da linhagem, coloca aquele que o recebe em herança como depositário do projeto familiar" (OFFROY, 2004, p. 123 apud RABAY, 2012, p. 73).

Com o histórico de parentes na política, ficou "mais fácil" para a prefeita inserir - se no campo do poder. Chegando a afirmar que "a política é muito importante por que muda a si mesmo e a vida das pessoas, é um espaço que traz muitas realizações pessoais e sociais". Sobre os motivos de sua inserção na política não hesita em dizer que foi por causa do pai e depois do esposo que também cogitou a ideia dela "entrar" na política. Afirma, entretanto, que passou a gostar de fazer política:

E gostei né! Descobri que eu podia fazer algo pelas pessoas. As pessoas começavam a lhe procurar e você se sentindo útil.

Sobre a disputa no núcleo familiar Glória Rabay (2012, p. 73) enfatiza:

O projeto familiar revelado na transmissão do prenome tende a perpetuar a reprodução do próprio grupo, o que não significa que o destinatário atenda passivamente aos apelos parentais ou que eles não sejam subvertidos por outros componentes do grupo. Pois, a herança provinda da família de origem pode significar concorrência dentro do núcleo familiar nas disputas por cargos eletivos.

As cinco prefeitas acumularam um capital político familiar, todas elas se candidataram levando o nome forte de políticos influentes da região onde venceram. $\mathrm{O}$ grau de parentesco delas com os políticos da região local, e que dominaram os municípios, durante décadas são de: filha, cunhada, esposa, viúva, irmã, sobrinha.

É importante destacar que o fato das mulheres estarem na política e muitas vezes serem herdeiras do capital familiar, demonstra as transformações ocorridas não apenas na política e na sociedade, mas também dentro do próprio âmbito familiar, em que muitas vezes estas mulheres têm irmãos e, no entanto, são as escolhidas para herdar a política por motivos específicos de cada interesse de grupo político, de família e de região.

É comum o esposo, o pai ou os filhos, indicarem a inserção das mulheres no campo político como forma de estratégia para manutenção do poder ou continuação da oligarquia local, é o parentesco nas relações sociais de poder político influenciando nas indicações eleitorais. Esta estratégia não acontece apenas em âmbito local, mas sim em todos os níveis de poder político, seja estadual ou nacional. Diante das falas das prefeitas, percebe-se que todas vieram dos laços de 
parentesco, seria muito mais difícil para uma mulher construir sua trajetória política sem se ancorar nos parentes políticos.

Lúcia Avelar (2001), uma das estudiosas da relação entre mulher e política, enfatiza que no Brasil a história da inserção feminina na política formal advém dentre outros fatores do poder oligárquico, em que as mulheres "entrariam” na política partidária para substituir os homens da família. Não temos a intenção de generalizar a afirmativa de que as mulheres entrevistadas se inseriram na política, devido apenas, aos familiares. Mas, afirmar que esta relação é muito presente na vida política delas, ainda é um peso muito forte para a participação de mulheres neste âmbito de poder.

Quanto à sua permanência na política, as mulheres continuam dependendo dos parentes, porém uma vez adquirindo experiência e "confiança" no grupo político do qual faz parte, saberiam conduzir, em parte, suas próprias ações e jogos de interesses mas não na totalidade. Porém, estando na política não seriam mais as mesmas mulheres, uma vez experimentando a prática política formal transformariam suas percepções sobre a esfera pública e privada, tanto em relação à condição de “ser mulher" como de ser "mulher política", mesmo estando "presas” às tradições da prática política local.

Glória Rabay e Maria Eulina (2010, p. 35) observa que na Paraíba muitas candidaturas de mulheres estão relacionadas às engrenagens do parentesco:

Com raras exceções, a maioria das mulheres (que ocuparam cargos eletivos no Estado) está ligada a esquemas eleitorais viciados e guarda relações de parentesco (era esposa, irmã ou filha) com algum político expressivo no cenário local. Além disso, utilizou estereótipos femininos para se eleger - a mãe sofredora, a benfeitora, a professorinha, a boa esposa, entre outros, indicando que uma retórica, uma manipulação da identidade feminina tradicional pode gerar dividendos políticos.

Corroborando com as ideias defendidas por Avelar (1987 apud RABAY: CARVALHO, 2010, p. 36) "poderíamos afirmar que a poderosa família política resolve todos os impedimentos estruturais e individuais, uma vez que libera, convida, inicia e apoia a mulher na vida pública e na política partidária”.

Uma pesquisa realizada na Bahia por Ana Alice Costa (1998) sublinhou a inserção das mulheres na política também pela via do parentesco. Ana Alice estudou o caso das mulheres políticas na Bahia entre 1982 à 1992 e destacou que das 127 vereadoras eleitas 120 destas mulheres 
tinham parentes na política, e 50 delas tinham diretamente relacionado à sua candidatura a um pai, um irmão ou esposo político.

A pesquisadora Ana Alice Costa (1998) não concorda com a ideia de que tais mulheres alcançaram uma verdadeira conquista feminina, uma autonomia política. Acredita que a inserção delas na política pela via do parentesco seria uma subordinação a mais, cuja conduta das mulheres políticas estaria dependente de quem as "colocou" no poder. A autora afirma que seria a ausência do "homem apto" para concorrer às eleições que faz com que a mulher seja convocada em lugar dele, ficando o mérito feminino ausente.

No entanto, vale salientar que ao participarem da política, mesmo com a força de grupos de poder locais, de parentes políticos, estas mulheres estariam construindo novas identidades culturais. Neste caso, o campo político está passando por lentas mudanças, mas na essência a sua prática política está preocupada com a força dos grupos políticos e o fortalecimento desta corporação (ALICE, 1998 apud RABAY; CARVALHO, 2010).

Neste contexto, é importante também ressaltar que há outras vias de acesso da mulher à esfera da política partidária. Os movimentos sociais ou o capital político, adquirido pelo reconhecimento por meio de ações sociais, são vias que também ajudam a mulher a ter projeção no universo da política. É o caso, por exemplo,

de artistas, de profissionais dos meios de comunicação de massa, de líderes de movimentos sociais e profissionais no campo da assistência social, que fazem (intencionalmente ou não) uma política informal, que atendam a necessidades concretas (RABAY; CARVALHO, 2010, p. 38).

As mulheres que se inseriram na política através de ações sociais têm uma relação com a comunidade traduzida em admiração, confiança, popularidade, carisma, simpatia e competência como seu maior trunfo. Tais atributos constituem o capital político das mulheres, em que são poucas aquelas que conseguem romper com a cultura tradicional e desempenhar um cargo público independente (RABAY; CARVALHO, 2010).

A via da própria militância política, requer, portanto, a liberação dos obstáculos inerentes ao papel tradicional, tanto no âmbito privado (a liberação dos encargos domésticos e familiares), quanto no âmbito público (o enfrentamento, neutralização ou reversão de preconceitos sexistas). Em suma, requer um fato extraordinário e heróico: que o poder pessoal se sobreponha ao poder patriarcal para que uma mulher ganhe (em verdade, construa) um capital político (os votos e os diversos apoios), a fim de investir e conquistar espaço em um partido, bem como indicações, representações, mandatos e cargos políticos. Isso sem considerar a questão do poder econômico fortemente patriarcal, que ao financiar as campanhas, 
restringe as possibilidades de independência de qualquer candidato (RABAY; CARVALHO, 2010, p. 39).

Diante disto, é inegável que a presença da mulher na política rompeu tabus sociais e convocou novas estruturas familiares, públicas, institucionais, individuais. As mulheres que, porventura, desejarem participar da política partidária devem revelar suas qualidades enquanto mulher e enquanto política, para sobrepor - se aos preconceitos de gênero e à subordinação familiar. Isto é, devem construir um capital político e firmar uma imagem pública convincente. Ao contrário das mulheres advindas de movimentos militantes que tem concretamente um capital simbólico e/ou mais possibilidade de desenvolvê-lo. Quando isso acontece estruturas da sociedade são abaladas e convoca a percepção de valores novos e valores tradicionais.

A própria inserção na militância política é uma quebra de obstáculos por parte das mulheres, tanto no âmbito doméstico ou familiar quando "comprovam" que o lugar das mulheres não é apenas o lar, o privado quando enfrentam o poder tradicional e conservador dos grupos políticos existentes. Certamente apesar de todas as barreiras enfrentadas pelas mulheres, a presença do feminino no poder significa transformações simbólicas no mundo da política (RABAY; CARVALHO, 2010).

Como citado anteriormente, a prefeita é de uma família de tradição política na Paraíba, seu pai já foi prefeito do município várias vezes, bem como seus tios, irmãos do pai. O irmão, que o acompanha na prefeitura, já foi vereador por seis mandatos consecutivos. A prefeita diz que "entrou na política" de "forma natural" por que sua família é de uma tradição política de quase trinta anos no município. Nasceu e cresceu ouvindo falar de política, mas mesmo assim nunca imaginou fazer parte dela. Pois, o que gostava mesmo era da política informal, ou seja, conviver em meio à comunidade ajudando as pessoas.

Ao afirmar "nós somos tradicionalmente políticos", a Prefeita evidencia o grupo político familiar, mas não admite que "entrou" na política por influência da família, mas por que seu nome foi citado várias vezes pelo partido do qual faz parte, o PSB: "Nós somos tradicionalmente políticos, então eu já tenho essa vivência na política”. A prefeita assumiu a vice prefeitura em 2004 e 2008, e naquela época o prefeito era o seu próprio tio. Porém, a gestora municipal nos lembra que não fazia parte de seus planos "entrar" na política formal:

Não estava dentro do projeto de vida tornar-se política. Eu gosto muito da política, me identifico muito com a política, mas gosto muito de fazer política para os outros que não sabe. Mas ser política eu nunca tive a pretensão em ser. Nunca ter sido a representatividade da política não. (Grifo nosso). 
Percebe-se que a institucionalização do poder feminino permanece na correspondência do mundo privado. A incorporação do poder no espaço público está para os homens, como afirma Flávia Biroli (2014, p. 52) corresponde "aos códigos e ao controle jurídico e burocratizado do Estado, com a simultânea diminuição dos âmbitos nos quais o poder informal das mulheres teria sido historicamente exercido, o doméstico e o sagrado".

Ora, a esfera familiar é importante para estas prefeitas e para as decisões políticas, pois os laços de parentescos dão forma às relações e ações que tais mulheres passam a constituir. Nesta valorização da família e dos parentes, as mulheres prefeitas surgem como figuras vulneráveis por que aparecem como sem autonomia para a entrada na esfera pública, e dependentes de astúcias do grupo de poder.

Outro exemplo é de uma das prefeitas reeleitas, no ano de 2012, que decidiu engajar-se na política formal pela vontade do pai e pelo fato de ter casado com o prefeito da cidade. Sem muito jeito para falar sobre sua inserção na política afirma que os motivos principais foram dois: o pai ter instigado a candidatura e o esposo que não poderia mais se candidatar porque já tinha sido prefeito do município várias vezes. Uma vez experimentando o espaço público passou a gostar. Ora, a ausência de identidade própria para candidatar-se é essencial para a confirmação de uma dependência de acesso ao poder político, o que impede muitas vezes a construção de uma identificação feminina no poder político partidário.

Há uma ausência de transformação social na entrada destas mulheres na política, isto transparece nas relações sociais, nos discursos, e nas práticas políticas que "adquiriram" na gestão do município. Pois, a forma como acontece a entrada e o continuísmo ou não destas mulheres na política está mais para uma subordinação que para um empoderamento do feminino no poder. Não apenas porque é facilitada pelos canais de parentesco mas porque as práticas e a forma de fazer política no interior do estado paraibano continuam as mesmas.

\section{Considerações finais}

As experiências do feminino na política estão relacionadas aos significados da ação política das prefeitas paraibanas, a percepção sobre a prática política de mulheres que exercem a gestão pública. Neste caso, é importante refletir sobre a representação de mulheres na política formal como 
enfatiza autores como (BARREIRA, 1998; AVELAR, 2001; RABAY, 2010) ao estudar a presença do feminino na política.

A participação das mulheres na prática política descortina um conjunto simbólico nem sempre claro nas arenas do poder, mas sim de um modo complexo. As mulheres que por diversos motivos decidiram candidatar-se e consequentemente se reelegeram provam que a imagem que constituíram, desde a primeira campanha eleitoral ao cargo de prefeita ou mesmo antes disso, foi significativa e importante para elas.

As prefeitas, mesmo relacionadas a interesses de parentes ou grupos políticos para se fazerem estar no campo de poder, um fato que não negam, assumem a experiência e a confiança que adquiriram durante a gestão pública. As qualidades que afirmam ter são resultados de muitos obstáculos, sejam os preconceitos, seja a dificuldade de acesso à política formal.

Chegar à política através de movimentos sociais é algo enobrecedor, ao passo que chegar à política pelo canal familiar seria algo empobrecedor, pois se estaria entrando em um campo de poder de "forma fácil”. “(...) Por detrás da crítica a essas mulheres parece haver uma visão de que a política deva ser somente vocação, e não uma carreira que exigiria um longo processo de formação" (GROSSI; MIGUEL, 2001, p. 192). É interessante o fato de que há mulheres que mesmo entrando na política por força familiar conseguem conquistar uma determinada independência que as fazem superar os preconceitos de gênero e ganhar prestígio no campo da política. A exemplo de uma das prefeitas entrevistadas (PSDB) que temia "entrar na política", mas que de forma muito independente afirma que assumiu a gestão do município sozinha e que iria certamente eleger sua candidata em eleições posteriores, tendo em vista que não poderia mais se candidatar por que já era reeleita. A Prefeita atua no modelo clientelista doando semanalmente mantimentos como feijão e carne de frango à população local. $\mathrm{O}$ que contribui para sua base eleitoral como forma de fortalecer e controlar os "ânimos" sociais.

Assim, para cada uma das prefeitas um valor específico chama atenção. Em seus discursos sacraliza-se uma realidade que para elas é de uma vasta relevância para continuarem na política, ou seja, a própria trajetória delas enquanto mulheres. Para elas a experiência na política começa muito difícil mas depois "vai melhorando" com o aperfeiçoamento da presença na política, das relações, dos comportamentos da ação política local.

Para cada prefeita eleita e reeleita é possível identificar nos municípios onde governam um contexto social, político, cultural e econômico diferente, embora muito parecidos: são cidades de pequeno porte, onde predomina o comércio e a agricultura local, e grande parte da população vive da aposentadoria e programas do governo federal. As intrigas políticas e o acirramento dos grupos 
políticos locais são marcas da política paraibana, ou seja, são características comuns nas disputas eleitorais dos municípios.

Eleger-se e ser representante do povo é também para elas como um "sacrifício de valor", ocupar um cargo público "não é para qualquer um, é para quem tem garra e desejo de lutar". Neste sentido, novas relações sociais, novos arranjos simbólicos são possíveis quando as mulheres participam da política formal. Mesmo que as decisões relevantes da política local, muitas vezes, não cabe à elas decidir, tais mulheres acabam assumindo de forma indireta um determinado poder, justamente por que passam a fazer parte dele. Talvez este seja um dos motivos pelos quais novos arranjos se redesenhem na política local paraibana, como o surgimento de mais mulheres candidatas, secretarias de governo e gestoras municipais. Mesmo que contribuam para continuar os grupos políticos de poder.

Percebe-se nas falas das prefeitas que as mesmas atuam na vida política para dar continuidade aos trabalhos familiares e de poder local, mesmo que assimilem uma presente desigualdade de gênero e tentem demonstrar independência, passam a assumir um papel social que projeta a relação de poder já concretizada na sociedade: as prefeitas levam os nomes dos políticos locais e devolve ou não à eles o mérito do jogo político. Dependendo de como as estratégias políticas ou eleitorais dão certo os grupos políticos, muitas vezes, vencem com a participação das mulheres na política.

\section{Referências}

AVELAR, Lúcia. As mulheres na elite política brasileira. São Paulo: UNESP, 2001.

BARREIRA, Irlys Alencar Firmo. Chuva de Papéis: ritos e símbolos de campanhas eleitorais no Brasil. Rio de Janeiro. Relume Dumará: Núcleo de Antropologia Política, 1998.

. Imagens Ritualizadas: apresentação de mulheres em cenários eleitorais. Campinas-SP, Pontes Editores, 2008.

BERNARDI, Jorge Luiz. Vereadoras de Curitiba: poder familiar e cotas de gênero. IN: OLIVEIRA, Ricardo Costa. Nepotismo, parentesco e mulheres. Curitiba: RMEditores, 2016.

BIROLI, Flávia. Autonomia, dominação e opressão. IN: MIGUEL, Luís Felipe; BIROLI, Flávia. Feminismo e política. São Paulo: Boitempo, 2014. 
BOURDIEU, Pierre. O Poder Simbólico. Rio de Janeiro, Bertrand, 2011.

COSTA, Ana Alice Alcântara. As donas do poder: mulher e política na Bahia. Salvador: NEIM/ UFBa - Assembléia Legislativa da Bahia, 1998.

OLIVEIRA, Ricardo Costa. Nepotismo, parentesco e mulheres. Curitiba: RMEditores, 2016.

RABAY, Glória; CARVAlHO, Maria Eulina Pessoa de. Mulher e Política na Paraíba: História de vida e luta. João Pessoa: Editora Universidade da UFPB. 2010.

RABAY, Glória. Mulheres na Política: As Filhas Herdeiras e a Força do Nome da Família. IN: FERREIRA, Maria Mary. (Org.). Gênero, Política e Poder: participação das mulheres nos espaços de poder no Norte e Nordeste. São Luís: EDUFMA, 2012, v. 1, p. 63-88.

\section{SITES CONSULTADOS:}

http://www.ibge.gov.br

http://www.tre-pb.jus.br

http://www.ste.jus.br

http://www.spm.gov.br 